\title{
COMPETITION BETWEEN THE REACTION MEDIUM AND NANOSTRUCTURED ZnO IN THE PHOTOCATALYTIC DEGRADATION OF ANTHRACENE. TOWARD AN OPTIMAL PROCESS FOR POLYCYCLIC AROMATIC HYDROCARBONS REMEDIATION
}

\author{
Blanca L. Martínez-Vargas ${ }^{a}$, Jesús A. Díaz-Reala ${ }^{\text {, }}$ Yolanda Reyes-Vidala $^{a}$ J. L. Rodríguez-López ${ }^{\text {b }}$ Raúl Ortega-Borges ${ }^{\mathrm{a}}$ and \\ Luis Ortiz-Frade ${ }^{\mathrm{a}, *}$ \\ aElectrochemical Department, Centro de Investigación y Desarrollo Tecnológico en Electroquímica, Parque Tecnológico Querétaro \\ Sanfandila SN, C. P. 76703, Pedro Escobedo, Querétaro, México. \\ ${ }^{b}$ Advanced Materials Department, Instituto Potosino de Investigación Científica y Tecnológica, A. C. Camino a la Presa San José \\ 2055, Lomas 4ª Secc. C.P. 78216, San Luís Potosí, México.
}

Recebido em 20/02/2016; aceito em 26/07/2016; publicado na web em 02/09/2016

\begin{abstract}
Contamination with polycyclic aromatic hydrocarbons (PAHs) is considered an important health issue due to the toxicity of these compounds. Photocatalytic degradation of anthracene, a representative molecule of PAHs, using the high quantum yield semiconductor $\mathrm{ZnO}$, has been reported. The solubility of anthracene in water makes necessary to use mixtures with organic solvents in fundamental degradation studies. It is well known that some organic solvents participate in the photochemical transformation of this molecule. In the PAHs photocatalysis, the competition between a semiconductor and solvents has not reported. Therefore, in this work, we decided to study the photocatalytic degradation of anthracene with two common reaction media and nanostructured $\mathrm{ZnO}$. The semiconductor was obtained by a one pot method which consists in an alkaline hydrolysis of $\mathrm{Zn}_{(}\left(\mathrm{CH}_{3} \mathrm{COO}\right)_{2} \cdot 2 \mathrm{H}_{2} \mathrm{O}$ in ethanol. Nanoparticles size in colloidal dispersion was calculated using UV-Vis spectroscopy and High Resolution Transmission Electron Microcopy (HR-TEM). ZnO powder was isolated and characterized by X-ray diffraction to be used in photocatalytic experiments. Surface area determination and photocurrent spectroscopic experiments were also carried out. Linear sweep voltammetries under darkness and UV-Vis irradiation indicate a charge separation due to photoexcitation. Photocatalytic experiments in ethanol:water pH 12 (1:1) and acetone:water $\mathrm{pH} 12$ (1:1), with and without $\mathrm{ZnO}$ was explored. The results demonstrated that ethanol:water and acetone:water promotes the photo-transformation of anthracene to 9,10-anthraquinone. Meanwhile, $\mathrm{ZnO}$ transformed anthracene to benzoic acid and to 9,10-anthraquinone in ethanol:water and acetone:water, respectively. A faster photochemical kinetic is observed when acetone was used as solvent in the presence and in the absence of $\mathrm{ZnO}$.
\end{abstract}

Keywords: $\mathrm{ZnO}$ nanoparticles; reaction medium; PAHs; photodegradation; anthracene.

\section{INTRODUCTION}

Anthropogenic activities have caused a wide distribution of polycyclic aromatic hydrocarbons (PAHs) in atmosphere, soil, sediment and water. This group of compounds has been associated with mutagenic and carcinogenic activity, which makes them dangerous for human health. ${ }^{1}$ The US Environmental Protection Agency (EPA) has included 16 of these compounds as priority pollutants. ${ }^{2}$ For this reason, oxidation degradation processes of PAHs including the model molecule anthracene have been reported. Microbial degradation has been used to achieve this goal. However, low efficiency and long time are the main disadvantages. ${ }^{3}$ Heterogeneous photocatalysis with nanostructured semiconductors has attracted recently interest, due to the low cost and high efficiency in the treatment of recalcitrant contaminants. The high quantum yield of $\mathrm{ZnO}$ and easy methods of preparation in comparison with other typical semiconductors such as $\mathrm{TiO}_{2}$ has been a motivation to use this material. ${ }^{4-6}$ Currently, there are few studies for the degradation of PAHs with synthetic $\mathrm{ZnO}$ and $\mathrm{GaN}: \mathrm{ZnO} .{ }^{7,8}$ In these type of studies the use of methanol, dichloromethane, acetonitrile, ${ }^{9}$ ethyl acetate and acetone ${ }^{10,11}$ is necessary due to the low solubility PAHs in water. On the other hand, it has been demonstrated that PAHs are photo-transformed in the presence of pure organic solvents or in water mixtures. ${ }^{12-14}$ This fact makes difficult to identify the role of solvent in the in the photochemical transformation of PAHs

*e-mail: lortiz@ cideteq.mx in the presence of semiconductors. Hence, we decided to study the photocatalytic reaction of anthracene, using nanostructured $\mathrm{ZnO}$ and two reaction media to understand the competition between the semiconductor $\mathrm{ZnO}$ and typical solvents (ethanol and acetone) in the transformation of a representative molecule of PHAs. This study is intended to design simpler methods to improve photocatalytic degradation of polycyclic aromatic hydrocarbons.

\section{EXPERIMENTAL SECTION}

\section{Reagents}

Zinc acetate dihydrate, $\mathrm{Zn}\left(\mathrm{CH}_{3} \mathrm{COO}\right)_{2} \cdot 2 \mathrm{H}_{2} \mathrm{O}$ (J. T. Baker, 99 $\%$ ); sodium hydroxide, $\mathrm{NaOH}$ (J. T. Baker, $98.2 \%$ ); ethyl alcohol absolute, $\mathrm{CH}_{3} \mathrm{CH}_{2} \mathrm{OH}$ (Aldrich $99 \%$ ); acetone, $\mathrm{CH}_{3} \mathrm{COCH}_{3}$ (Aldrich $99 \%$ ); hydrochloric acid, $\mathrm{HCl}$ (J. T. Baker; $37.3 \%$ ); anthracene, $\mathrm{C}_{14} \mathrm{H}_{10}$ (Aldrich $99 \%$ ); dichloromethane, $\mathrm{CH}_{2} \mathrm{Cl}_{2}$ (J. T. Baker $99 \%$ ); were used without further purification; multicomponent solution (RESTEK $99 \%)$; ultrapure water $\left(18 \mathrm{M} \Omega \mathrm{cm}^{-1}\right)$ was obtained from a UV Millipore system.

\section{Synthesis of colloidal $\mathrm{ZnO}$ nanoparticles}

$\mathrm{ZnO}$ nanoparticles in colloidal dispersions were obtained by a modification of a previously described method, ${ }^{15}$ which presents the advantage of being a one pot synthesis. The reaction corresponds to a simple alkaline hydrolysis of zinc acetate (Equation 1). $0.011 \mathrm{~g}$ 
$(0.0272 \mathrm{mmol})$ of $\mathrm{Zn}\left(\mathrm{CH}_{3} \mathrm{COO}\right)_{2} \cdot 2 \mathrm{H}_{2} \mathrm{O}$ was dissolved in $25 \mathrm{~mL}$ of ethanol at room temperature, followed by the addition of $0.325 \mathrm{~mL}$ of $0.2 \mathrm{~mol} \mathrm{~L}^{-1} \mathrm{NaOH}$ in ethanol solution. The reaction mixture was heated for 2 hours at $60^{\circ} \mathrm{C}$.

$\mathrm{Zn}\left(\mathrm{CH}_{3} \mathrm{COO}\right)_{2}-2 \mathrm{H}_{2} \mathrm{O}+2 \mathrm{NaOH} \stackrel{E t O H}{\longrightarrow} \mathrm{ZnO}+2 \mathrm{Na}\left(\mathrm{CH}_{3} \mathrm{COO}\right)+\mathrm{H}_{2} \mathrm{O}$

The obtained colloidal dispersion was characterized by UV-Vis spectroscopy, using a Thermo Scientific Evolution Array spectrophotometer. Emission spectra was acquired with a spectrofluorometer Horiba Jobin Yvon/Fluorolog $\left(\lambda_{\text {exc }}=350 \mathrm{~nm}\right)$ from 315 to $800 \mathrm{~nm}$. The morphology and size distribution of the $\mathrm{ZnO}$ nanoparticles were studied by high-resolution transmission electron microscopy (HR-TEM) (Tecnai F30-300 kV).

\section{Isolation and characterization of $\mathrm{ZnO}$ powder}

Freshly prepared colloidal dispersion of $\mathrm{ZnO}$ nanoparticles in ethanol was concentrated by slow evaporation with airflow over the solution, using a commercial $12 \mathrm{~V}$ fan until a slurry white solution was obtained. The dispersion was centrifuged at $3500 \mathrm{rpm}$ for 20 minutes. A white powder was separated and washed with ethanol and acetone. XRD analyses were performed placing the sample over a glass slide, using a Bruker-AXS D8 advance diffractometer $\left(\mathrm{Cu} \mathrm{K}_{\alpha} \lambda=1.5406 \AA\right)$. The collected data was refined by the Rietveld method using the software FULLPROF SUITE. ${ }^{16,17}$ Thompson-CoxHastings pseudo-Voight function was used to model peak shape and preferred orientation. The background was modeled as a polynomial with 6 refined coefficients. The nitrogen adsorption-desorption isotherms were recorded using an Autosorb $\mathrm{iQ}_{2}$ equipment. The specific surface area was calculated by applying the BET equation to the nitrogen adsorption isotherm and the Barret-Joyner-Halenda (BJH) method to desorption branch of the nitrogen isotherm, respectively.

\section{Electrochemical characterization}

Electrochemical characterization was performed using $\mathrm{ZnO}$ deposit over photo-electrodes prepared by spin-coating technique with a home-made device, see Scheme 1. A $\mathrm{ZnO}$ suspension (15 mg mL $\mathrm{mg}^{-1}$ in ethanol) added at rate $60 \mu \mathrm{L} \mathrm{min}{ }^{-1}$ with a rotating speed of $1800 \mathrm{rpm}$ over a conducting glass substrate (SOLEMS, FTO 20 omhs). After spin-coating, a thermal annealing was performed at $200{ }^{\circ} \mathrm{C}\left(10^{\circ} \mathrm{C} \mathrm{min}^{-1}, 1 \mathrm{~h}\right)$ under air. Electrical contact to the FTO was done with silver conducting paint (Radio Spares, 186-3593) to a copper wire and isolated with epoxy resin (3M, Scotch-weld DP-190). For all the experiments, a $0.1 \mathrm{~mol} \mathrm{~L}^{-1} \mathrm{NaOH}$ solution ( $\mathrm{pH}$ 12.9) outgassed with $\mathrm{N}_{2}$ was used as supporting electrolyte. The electrochemical measurements were performed at $25{ }^{\circ} \mathrm{C}$ in a three-electrode cell equipped with a quartz window, using a SP-300 Bio-logic potentiostat-galvanostat. A glassy carbon electrode and a reversible hydrogen electrode (RHE) served as counter and reference electrode, respectively.

\section{Linear sweep voltammetry}

Linear sweep voltammetry (LSV, $v=5 \mathrm{mV} \mathrm{s}^{-1}$ ) measurements were performed in a potential range from -0.2 to $1.2 \mathrm{~V} / \mathrm{RHE}$ in the presence and in the absence of light. Photocurrent transient curves ( $\mathrm{v}=5 \mathrm{mV} \mathrm{s}^{-1}$ ) were obtained by light chopping (Lambda SC shutter controller) with on-off periods of $10 \mathrm{~s}$. The effective irradiance power at electrode distance was $34 \mathrm{~mW} \mathrm{~cm}^{-2}$ using a $175 \mathrm{~W}$ Xenon lamp (Spectral Products ASB-XE-175EX polychromatic source).

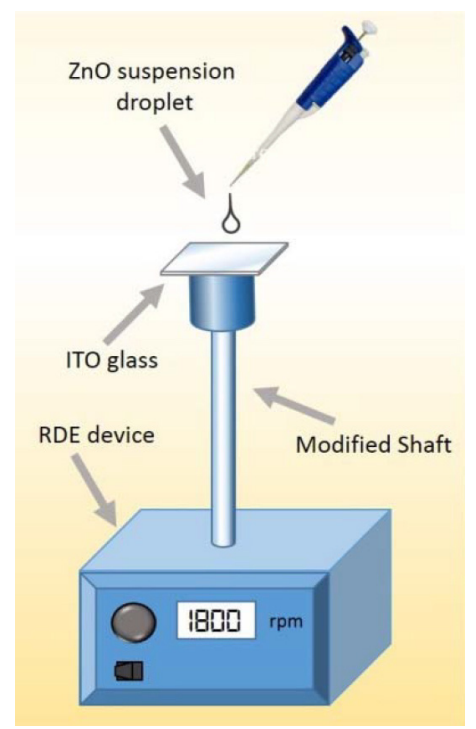

Scheme 1. Home-made spin-coating experimental setup. An rpm controllable device is modified to hold and rotate an ITO glass piece at $1800 \mathrm{rpm}$ while dropping the prepared suspensions at an addition rate of $60 \mu \mathrm{L} \mathrm{min}{ }^{-1}$ to cast a thin layer over the conductive glass

\section{Photocurrent spectroscopy}

Photocurrent spectroscopy measurements were recorded with electrode polarization at 1.0 V/RHE and scanning wavelengths from $305 \mathrm{~nm}$ to $550 \mathrm{~nm}$ using a $175 \mathrm{~W}$ Xenon lamp (Spectral Products ASB-XE-175EX polychromatic source) coupled to a motorized monochromador (Horiba Jobin Ybon 0106-07-07). The quantum yield was also evaluated by photocurrent action spectra measurements. After lamp spectrum normalization, the IPCE (Incident Photon-toelectron Conversion Efficiency) was obtained.

\section{Photocatalytic experiments}

Photocatalytic experiments were performed at room temperature using a single $15 \mathrm{~W}$ UVC lamp with emission at $254 \mathrm{~nm}$ in order to avoid recombination processes. A quartz cell with PTFE stopper and path length of $1 \mathrm{~cm}$ was used as batch reactor. The distance between the cell surface and the lamp was $8 \mathrm{~cm}$. The irradiation power $(31.4$ $\mu \mathrm{W} \mathrm{cm}^{-2}$ ) was measured with a Radiometer Cole-Parmer UVX. A volume of $3.5 \mathrm{~mL}$ of anthracene was used, in a concentration of $20 \mathrm{ppm}$ in ethanol:water $\mathrm{pH} 12$ or acetone:water $\mathrm{pH} 12$ solutions (1:1). Experiments in absence and in the presence of $1.5 \mathrm{mg}$ of $\mathrm{ZnO}$ nanoparticles powder were carried out separately. The reaction solution was stirred in darkness for five minutes to establish the adsorption/ desorption equilibrium of anthracene on $\mathrm{ZnO}$ surface. Photocatalysis of anthracene (20 ppm) in pure ethanol and pure acetone were also evaluated. The total time in photocatalytic experiments was 60 minutes. UV-vis spectra were measured every 5 minutes changing the quartz cell from the photoreactor to the spectrophotometer. At end of reaction time, the mixture centrifuged to remove the photocatalyst. Then, volatile products were extracted with dichloromethane. The resulting solutions were analyzed by a gas chromatograph (Agilent 68.90 plus) containing a column of HP-5ms (5\%-phenyl)-methylpolysiloxane, coupled to a mass spectrometer (Agilent 59.73). Chromatographic analysis of solutions exposed directly to UV radiation was performed using a Waters (México) H-Class Acquity ultra-performance liquid chromatography system (UPLC), which included a quaternary solvent manager, photodiode array detector (PDA), cooling autosampler and an oven for analytical column. Chromatographic data were collected 
and processed by Waters Empower3 chromatography software. Chromatographic separation was achieved on a Waters UPLC BEH C18 column ( $50 \mathrm{~mm}$ x $2.1 \mathrm{~mm}$ i.d., $1.7 \mu \mathrm{m})$, using a mobile phase composed of acetonitrile:water, 50:50 (v:v) at a flow rate of $0.4 \mathrm{~mL} \mathrm{~min} \mathrm{mi}^{-1}$, a column temperature of $30^{\circ} \mathrm{C}$ and an injection volume of $10 \mu \mathrm{L}$. A PDA detector system was employed obtaining chromatograms by recording a multi-wavelength set in the wavelength range $200-800 \mathrm{~nm}$. Anthracene, 9,10-anthraquinone, and benzoic acid in different reaction media, with concentration ranging from $1 \mathrm{ppm}$ to $20 \mathrm{ppm}$, were used as reference solutions for calibration curves. To separate $\mathrm{ZnO}$ residues, samples and standards were filtered using a $0.2 \mu \mathrm{m}$ nylon membrane.

\section{RESULTS AND DISCUSSION}

\section{Synthesis and characterization of colloidal $\mathrm{ZnO}$ nanoparticles}

In order to demonstrate the formation of $\mathrm{ZnO}$ in colloidal dispersion, UV-vis and emission spectrums were acquired. Figure 1a) shows a typical electronic absorption band edge at $367 \mathrm{~nm}$, characteristic of $\mathrm{ZnO}$ nanoparticles in colloidal dispersion. Using this value, and according to the Wannier exciton model, it was possible to calculate a nanoparticle size considering spherical shape and the band gap value; of $5.18 \pm 0.3 \mathrm{~nm}$ and $3.4 \mathrm{eV}$, respectively. ${ }^{18-22}$

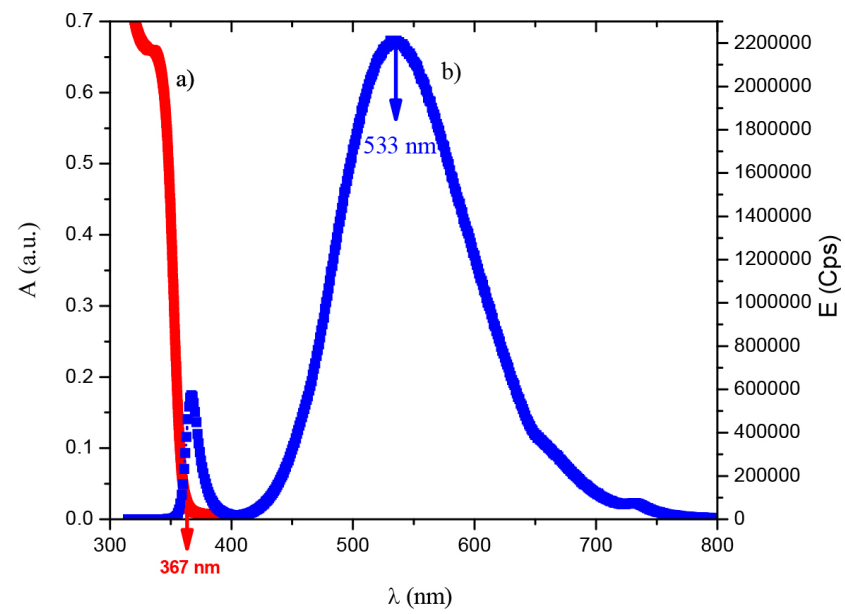

Figure 1. a) UV-vis absorption spectrum and b) Emission spectrum of the colloid of $\mathrm{ZnO}$ nanoparticles in ethanol

In Figure 1b) a broad green emission peak at $533 \mathrm{~nm}$ is observed when the sample is excited at $350 \mathrm{~nm}$. This response could be related to surface defects such as singly ionized oxygen vacancy $\left(\mathrm{V}_{\mathrm{O}+}\right)$, described by Vanheusden K. et al. ${ }^{23}$ the oxygen vacancy is an intrinsic donor in $\mathrm{ZnO}$, suggesting that there are reactive sites with low recombination. ${ }^{24-26}$ Figure 2 shows a selected HR-TEM image of $\mathrm{ZnO}$ nanoparticles. Typical $\mathrm{d}_{\mathrm{hkl}}$ distances for wurtzite (hexagonal) $\mathrm{ZnO}$ phase were observed. By counting over 100 particles, a polydisperse size distribution nanoparticles ranging from $3.5 \mathrm{~nm}$ to $5.5 \mathrm{~nm}$ was calculated.

\section{Characterization of the isolated powder of $\mathrm{ZnO}$ nanoparticles}

For photocatalytic experiments, semiconductor powder was isolated. Hence, a completed characterization is presented in this section. Figure 3 shows a typical $\mathrm{X}$-ray pattern of the $\mathrm{ZnO}$ powder. In the same graph, its corresponding Rietveld refinement plot is shown, indicating that the sample presents a wurtzite-type structure (JCPDS 89-1397). A good concordance between experimental and calculated diffraction patterns was observed. Nanoparticle size of $5.2 \pm 0.1 \mathrm{~nm}$ was calculated using the Debye-Scherrer equation.
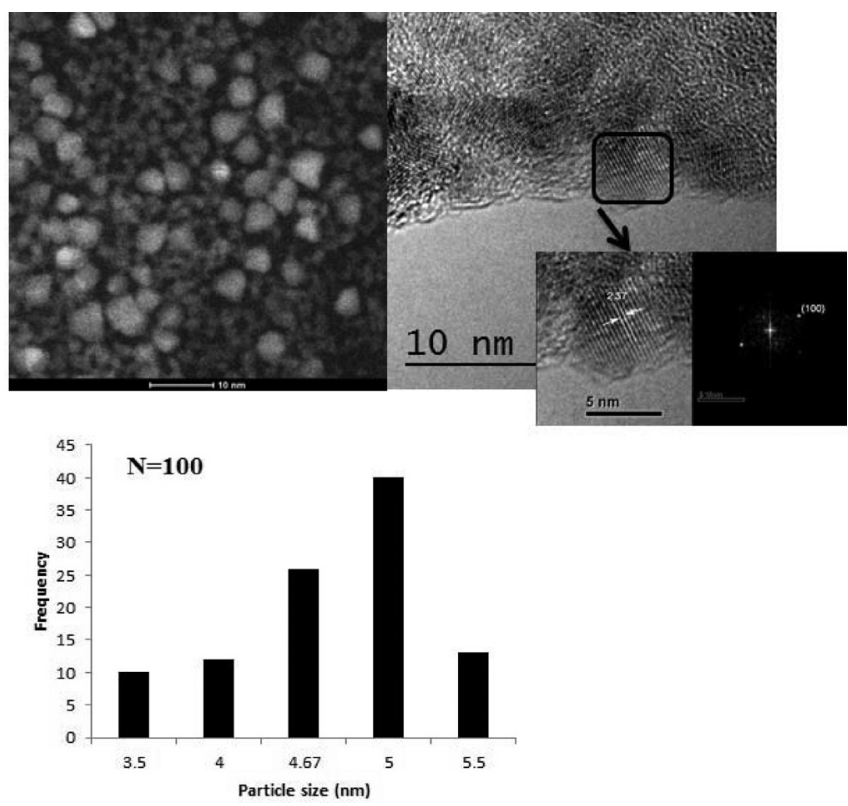

Figure 2. HR-TEM micrograph selected of $\mathrm{ZnO}$ nanoparticles and its size distribution

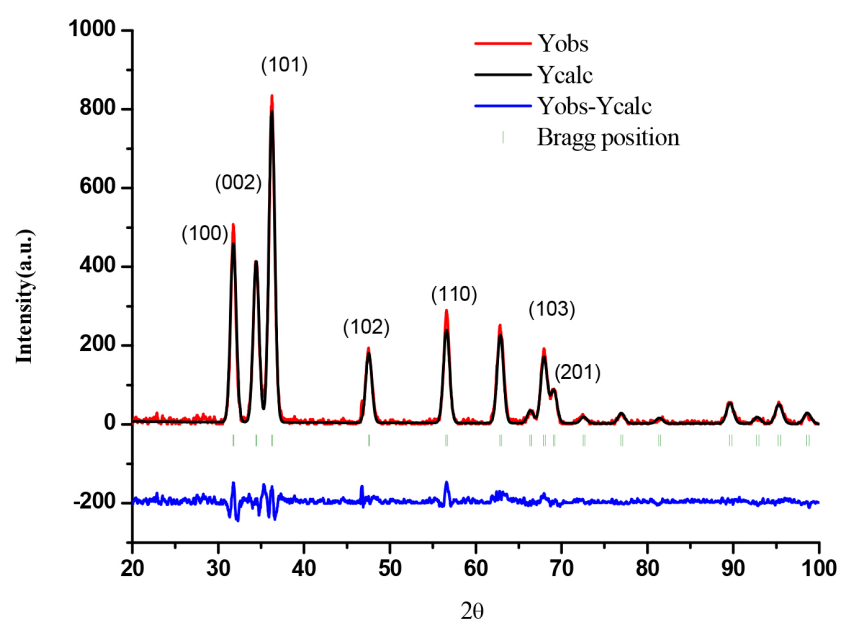

Figure 3. X-Ray pattern diffraction of $\mathrm{ZnO}$ nanoparticles powder and its corresponding Rietveld refinement plot. Space group $\mathrm{P}_{3} m c, a=3.252 \AA, b$ $=3.252 \AA, c=5.2102, \alpha=90^{\circ}, \beta=90^{\circ}, \gamma=120^{\circ}, \chi^{2}=2.0, R_{w p}=0.269, R_{p}$ $=0.165, R_{\text {exp }}=0.1765$

The surface area, calculated by the BET (Brunauer-Emmett-Teller) method shows a higher value for the synthesized colloidal $\mathrm{ZnO}\left(\mathrm{S}_{\mathrm{BET}}=\right.$ $\left.122.22 \mathrm{~m}^{2} \mathrm{~g}^{-1}\right)$ in comparison with commercial $\mathrm{ZnO}\left(\mathrm{S}_{\mathrm{BET}}=12.94 \mathrm{~m}^{2}\right.$ $\left.\mathrm{g}^{-1}\right)$. Figure 4 shows a typical adsorption-desorption isotherm, which according to IUPAC correspond to a mesoporous solid (type IV) with multilayers adsorption. Another characteristic observed from the isotherms is the difference between the adsorption and desorption curves, which suggests the possible development of hysteresis due to irregular capillary condensation, that can be understood as a process where a vapor phase (water) fills the porous of a material with a condensation of this phase and is related to an increase of Van der Waals interaction between molecules within the porous of material. ${ }^{27}$

\section{Electrochemical characterization and band gap determination}

Linear weep voltammetries under illumination and darkness using ZnO-FTO electrodes were carried out to demonstrate photo-induced 


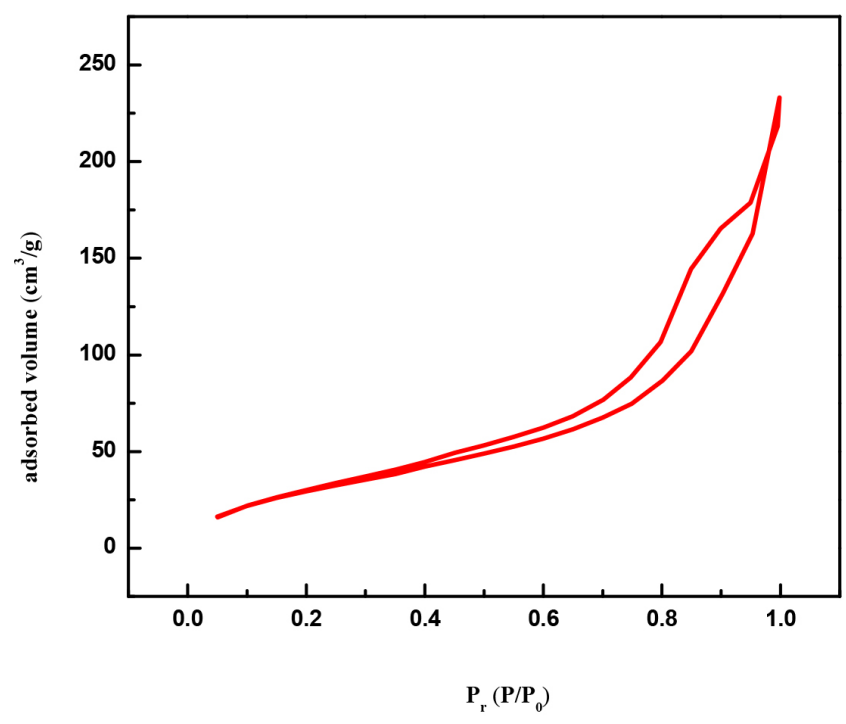

Figure 4. Adsorption-desorption isotherms of $\mathrm{ZnO}$ isolated powder $\mathrm{S}_{B E T}=$ $122.22 \mathrm{~m}^{2} \mathrm{~g}^{-1}$

charge separation and for band gap determination. Figure 5, shows a typical I vs E plot, where it can be observed at around $0.07 \mathrm{~V} / \mathrm{RHE}$ where an electron-hole pair $\left(\mathrm{e}^{-} / \mathrm{h}^{+}\right)$separation process with no significant differences on $\mathrm{E}_{\text {onset }}$. It is important to remark that, for semiconductor electrodes, the recombination is manifested as negative spikes in current density when illumination is cut-off, depending on the surface states and structural defects that are overcome when a strong electric field is achieved at high over potential in comparison with $\mathrm{E}_{\text {onset. }}$ In this case, the photocurrent, where recombination is not presented at E > 0.5 V/RHE. This is also confirmed by the chronoamperometric measurements presented in Figure 6. These experiments were recorded while polarizing at $1.0 \mathrm{~V} / \mathrm{RHE}$ allowing the electrode to reach a stable current (dark current) and then irradiating it with polychromatic (UVVis) light. From such curves it is possible to conclude a very fast onset (On) and decay (Off) response to irradiation, which is analog to Figure 5 in the same potential range..$^{28,29}$

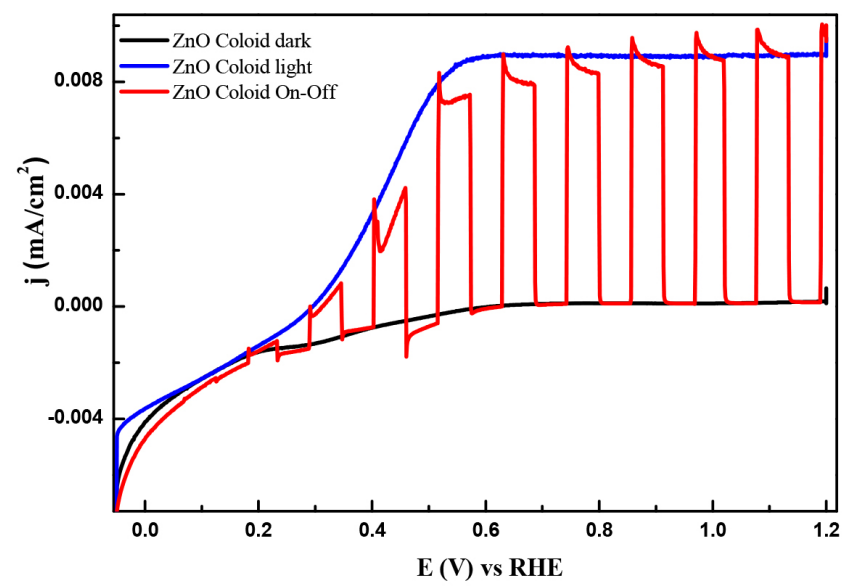

Figure 5. Linear sweep voltammograms recorded for the prepared $\mathrm{ZnO}$ electrodes under darkness, $U V$-Vis light and transient curves. $V=5 \mathrm{mV} \mathrm{s}^{-1}$ with $\mathrm{I}=34 \mathrm{~mW} \mathrm{~cm}^{-2}$

The quantum yield was also evaluated by photocurrent action spectra measurements. These measurements were recorded while the electrodes were polarized at 1.0 V/RHE and the wavelengths was scanned from 305 to $550 \mathrm{~nm}$. From linear voltammetry it was established that when the electrodes are polarized at high potential

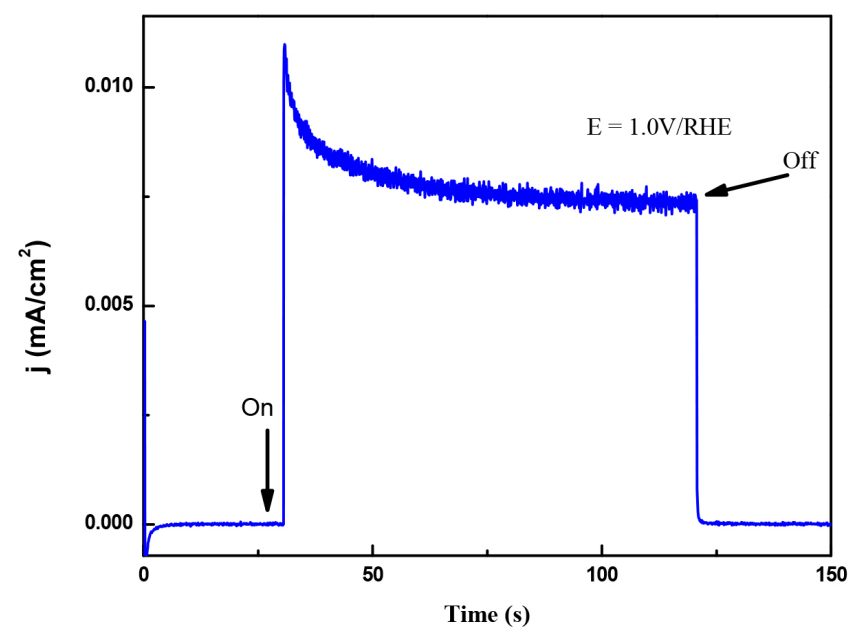

Figure 6. Chronoamperometric (1.0 V/RHE) response when UV-Vis light was irradiated (on) and interrumpted (off)

values no recombination was observed and therefore reliable photocurrent spectroscopy could be measured. The IPCE (Incident Photon-to-electron Conversion Efficiency) is shown in Figure 7a). The absorption edge for colloidal $\mathrm{ZnO}$ occurs at $\lambda_{\text {onset }}=395 \mathrm{~nm}$. Figure $7 b)$ shows the Tauc plots for these electrodes, where the band-gap (Eg) was obtained from the intersection with $\mathrm{X}$-axis (photon energy) of an extrapolated straight line where the absorption edge starts, see equation 2. The Eg value was $3.15 \mathrm{eV}$, which is smaller than the commercial material $3.22 \mathrm{eV}$.

$$
(I P C E \times h v)^{2} \alpha(h v-E g)
$$

\section{Stability of $\mathrm{ZnO}$ for photocatalytic experiments}

The selection of $\mathrm{pH}$ for photocatalytic test was based on $\mathrm{ZnO}$ predominance diagrams (see Figure 8), calculated with Hydra Medusa software. In a similar experimental conditions and according to literature. It can be observed that for $\mathrm{pH}>8$ the predominant species is $\mathrm{ZnO}^{30}$

\section{Competition between ethanol:water and $\mathrm{ZnO}$ in the photocatalytic degradation of anthracene}

Photochemical competition between ethanol and $\mathrm{ZnO}$ in anthracene transformation under UV radiation at $254 \mathrm{~nm}$ was studied using UV-visible absorbance measurements at 325, 340, 357, and 377 $\mathrm{nm}$, characteristic of $\pi \rightarrow \pi^{*}$ electronic transitions. Figure 9 shows a typical degradation efficiency $\left(\mathrm{C}_{\mathrm{t}} / \mathrm{C}_{0}\right)$ vs. time plot for pure (a) ethanol, (b) ethanol:water $\mathrm{pH} 12$ and (c) $\mathrm{ZnO}$-ethanol:water $\mathrm{pH}$ 12. When pure ethanol was used, the degradation of anthracene did not occur. On the other hand in reaction system containing ethanol:water $(\mathrm{pH} 12)$ a degradation efficiency of $30 \%$ was recorded at 25 minutes. After this time anthracene was not detected, yielding a yellowish solution with two new signals at 450 and $375 \mathrm{~nm}$, associated to the presence of anthraquinone derivatives. ${ }^{31,32}$ In the presence of $\mathrm{ZnO}$ no change in color solution was observed and a degrataion efficiency of $60 \%$ was achived at 55 minutes. Using integrated rate equations for chemical kinetic analysis the systems ethanol:water $\mathrm{pH} 12$ in the presence and in the absence of $\mathrm{ZnO}$ presented a first-order reaction, with similar reaction-rate constant values. Table 1 summarizes kinetic parameters obtained by fitting data. ${ }^{33}$

A comparison between these kinetic parameters suggests a similar reaction mechanism at initial times. However, the fact that 

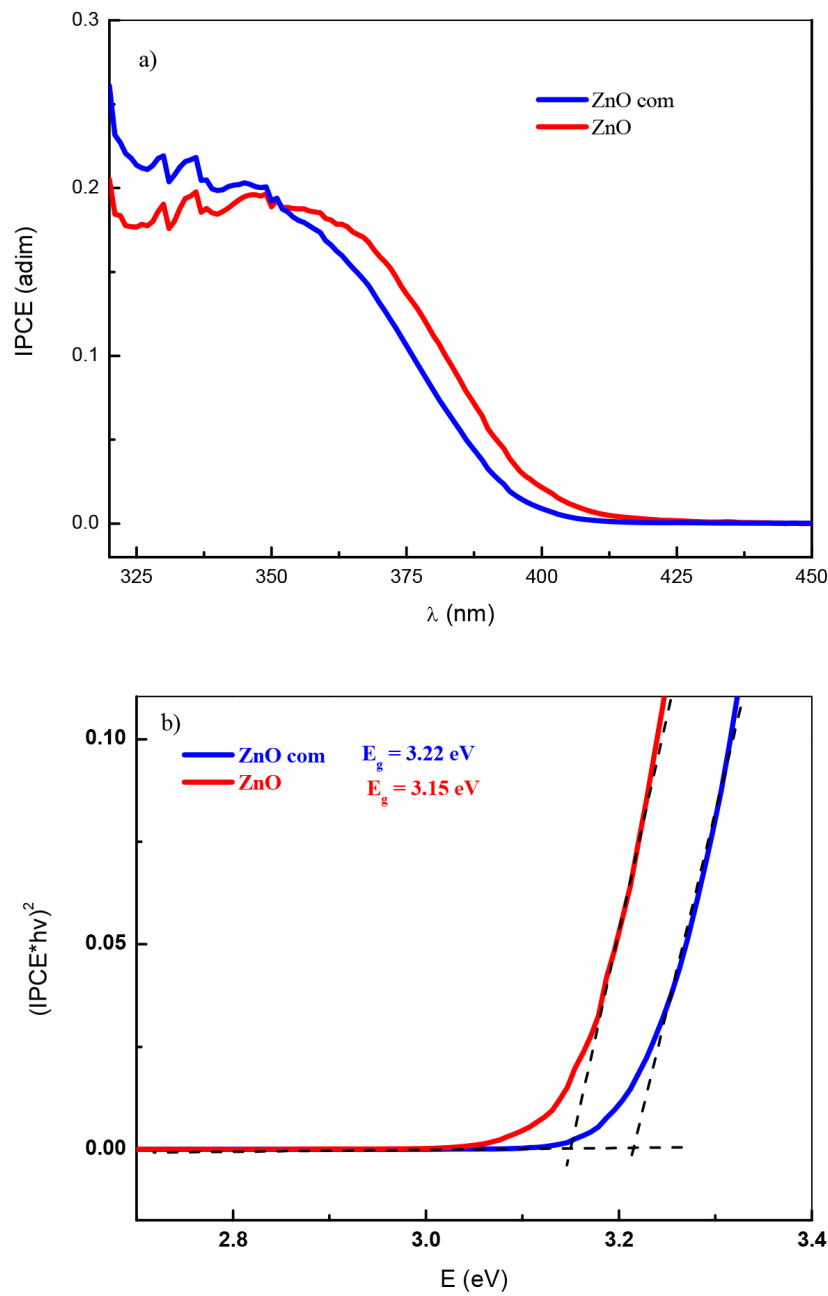

Figure 7. a) Photocurrent action spectra (normalized to lamp spectrum) for $\mathrm{ZnO}$ when polarized at 1.0V/RHE. b) Tauc plots for the same electrodes for a direct electronic transition excitation process $(a=2)$. Wavelength scan rate $=10 \mathrm{~nm} \mathrm{~s}^{-1}$ with $\mathrm{I}=34 \mathrm{~mW} \mathrm{~cm} \mathrm{~cm}^{-2}$ (for polychromatic light)

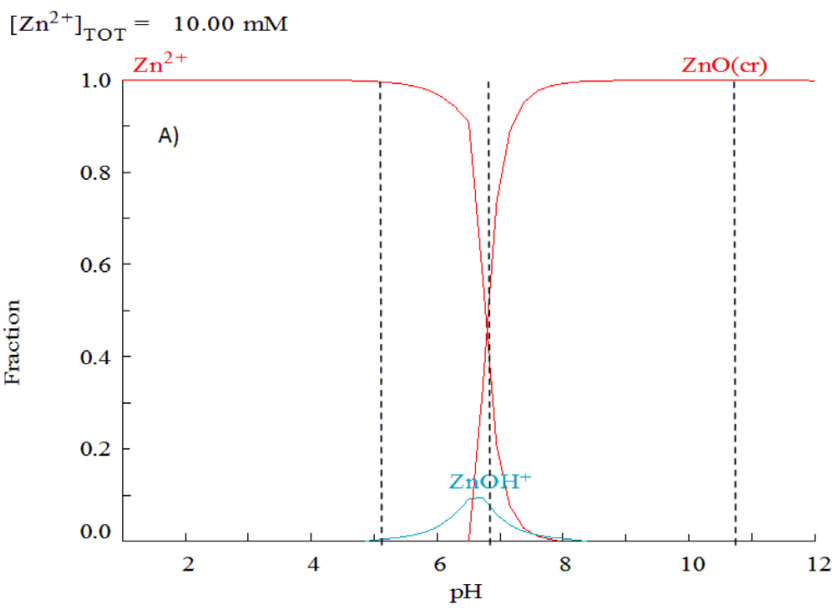

Figure 8. Predominance diagram, estimated with Hydra and Medusa software

anthracene is detected at longer photocatalysis time (55 minutes) in the presence of semiconductor, suggests a parallel degradation pathway. Extracted solutions with $\mathrm{CHCl}_{3}$ for both cases were analyzed using gas chromatography coupled to mass spectrometry (GC/MS). Figure 10 shows gas chromatograms in $\mathrm{CHCl}_{3}$ for (a) anthracene standard solution (20ppm) and the obtained extracts from (b)

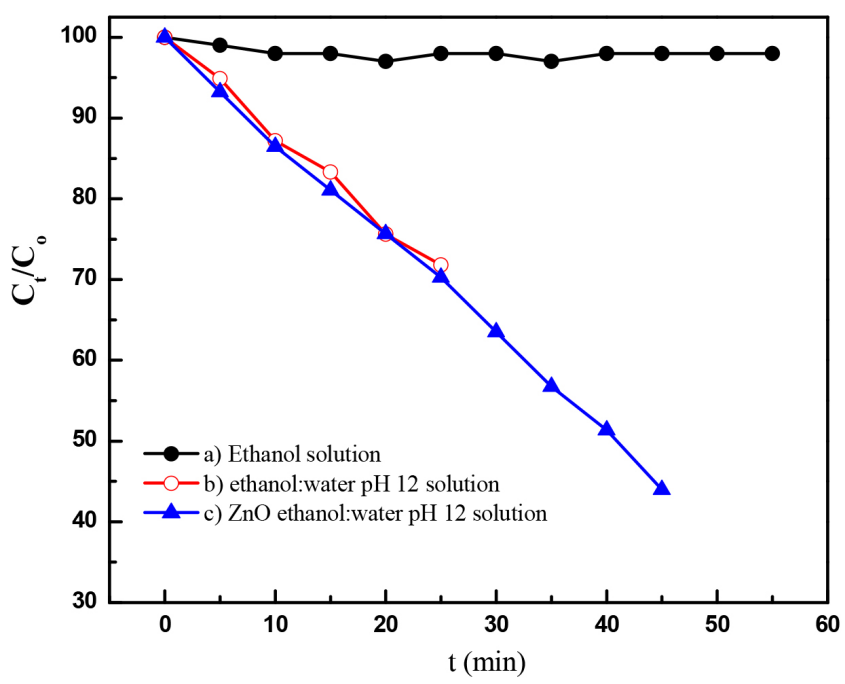

Figure 9. Anthracene degradation efficiency $\left(C_{t} / C_{0}\right)$ vs time graph in a) ethanol solution, b) ethanol:water pH 12 solution and c) ZnO ethanol:water pH 12 solution, exposed to a $15 \mathrm{~W}$ UV lamp at $254 \mathrm{~nm}$, irradiation power $\left(31.4 \mu W \mathrm{~cm}^{-2}\right)$

photolysis solution (ethanol:water $\mathrm{pH}$ 12) and from (c) photocatalytic solution (ZnO-ethanol:water $\mathrm{pH} 12$ ). A decrease in ion abundance for signal at retention time value of $20.55 \mathrm{~min}$, associated to anthracene is registered. It can also be observed a new signal at $22.70 \mathrm{~min}$ retention time, attributed to 9,10-anthraquinone. Mass spectrum of the aforementioned signals confirm this assertion, see Figure 11

In order to identity products in solutions exposed directly to UV radiation, ultra-performance liquid chromatography (UPLC) with photodiode array detector (PDA) was carried out. Figure 12 shows UPLC chromatogram for the $\mathrm{ZnO}$-ethanol:water $\mathrm{pH} 12$ solutions exposed to UV radiation after 60 minutes. The chromatogram shows signals at retention time values of $0.261,1.37$, and $4.399 \mathrm{~min}$, with their corresponding UV-vis spectra. This figure allows us to state the presence of 9,10-anthraquinone (54\%), benzoic acid (35\%) and anthracene (1\%), due to the same retention times and UV-vis spectrum of standard solutions. This analysis was done for all the other solutions exposed to UV radiation. A summary of percentage (\%) of each compound in all solutions are presented in Table 1. In a general trend 9,10-anthraquinone is the main product in ethanol:water $\mathrm{pH} 12$, meanwhile $\mathrm{ZnO}$, promotes the formation of a more oxidized byproduct, benzoic acid.

According to literature, it is possible to propose that for initial times the determinant step is hydroxyl radicals $(\mathrm{OH} \cdot)$ generated from $\mathrm{OH}^{-}$or $\mathrm{H}_{2} \mathrm{O}$. At long times, hydroxyl radicals $(\mathrm{OH} \cdot)$ from a separation charge process of $\mathrm{ZnO}$, react in low energetic sites of anthracene, producing 9,10-anthraquinone, or a more oxidized compounds such as benzoic acid. ${ }^{34-36}$ This experimental evidence is in agreement with reactivity sites described by $\mathrm{Nu}$ (Dewar) values for the positions of anthracene, ${ }^{37-39}$ see Figure 13, where the positions 9 and 10 are preferentially attacked. ${ }^{40}$

\section{Photocatalytic reaction of anthracene in acetone:water in the presence and in the absence of $\mathrm{ZnO}$}

Figure 14 shows a typical degradation efficiency $\left(\mathrm{C}_{\mathrm{t}} / \mathrm{C}_{0}\right)$ vs. time graph for (a) pure acetone, (b) acetone:water $\mathrm{pH} 12$ and (c) $\mathrm{ZnO}$ acetone:water $\mathrm{pH} 12$ exposed to a UV radiation $(254 \mathrm{~nm})$. In the reaction systems (b) and (c) anthracene absorption signals are not presented after 15 minutes. A change in color solution from colorless to yellow associated to the presence of anthraquinone derivatives, with 


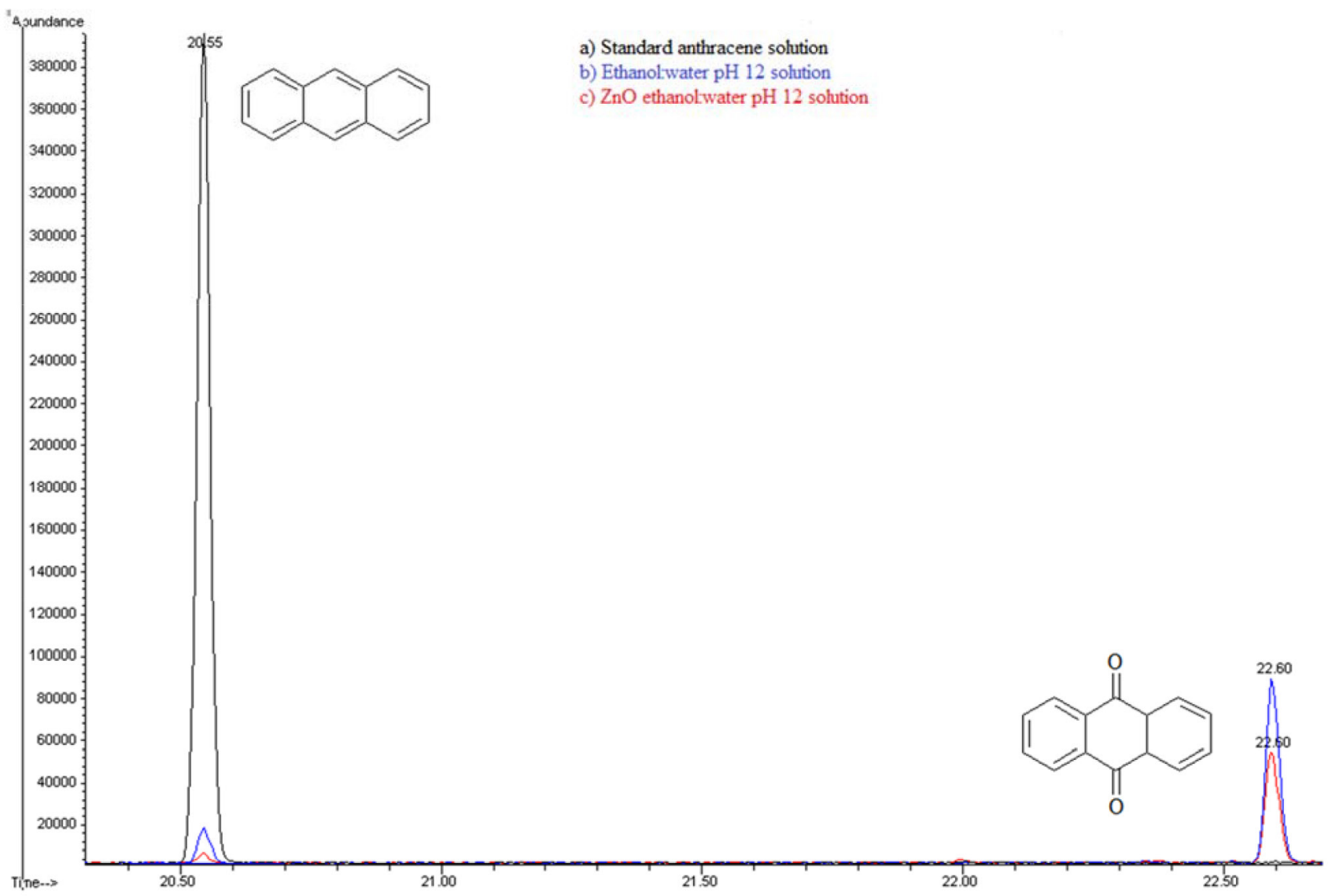

Figure 10. Gas Chromatography of a) Standard anthracene 20ppm b) Extract from ethanol:water pH 12 solution c) Extract from ZnO-ethanol water pH 12 solution
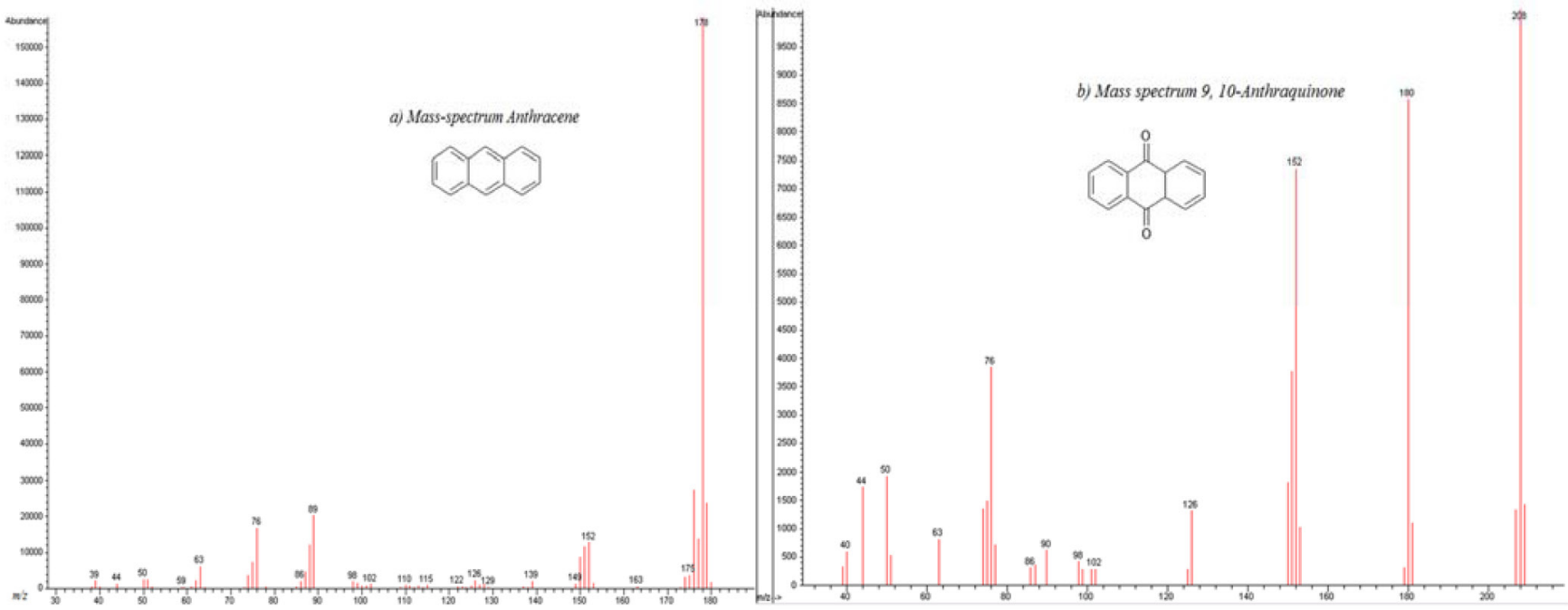

Figure 11. Experimental Mass spectra of: a) Anthracene at $R t=20.55$ min and b) 9, 10-anthraquinone at Rt=22.60 min

absorption signals at $395,423,476 \mathrm{~nm}$, are also observed. ${ }^{31,32}$ In the presence of pure acetone (a) anthracene is still detected near to 50 minutes of photolysis. No changes in color solution were observed. Using chemical kinetic analysis, all systems presented a zero-order reaction. For acetone:water $\mathrm{pH} 12$ and $\mathrm{ZnO}$-acetone:water $\mathrm{pH} 12$ the same reaction rate constant value for anthracene photo-transformation was calculated, which is lower than that obtained for pure acetone, see Table 2.

In order to explore the presence of byproducts, (GC/MS) and (UPLC), with a photodiode array detector (PDA) were also carried out. In the extracts obtained from all conditions, in GC/MS, the only detectable compounds were anthracene and 9,10-anthraquinone, at retention time values at 20.52 and 22.60 minutes respectively, see Figures 15 and 16. Using (UPLC-PDA) the presence of anthracene and 9,10-anthraquinone was confirmed in the reaction media $\mathrm{ZnO}$ acetone:water $\mathrm{pH} 12$, see Figure 17. A summary of percentage (\%) of the main compounds in all the photo-transformations are presented in Table 2. It should be highlighted that 9,10-anthraquinone is the main product in acetone:water $\mathrm{pH} 12$ in the presence or in the absence of $\mathrm{ZnO}$. A detail inspection of the chromatograms in Figures 17 ( $\mathrm{ZnO}-$ acetone:water $\mathrm{pH}$ 12, photocatalysis) and Figure 18 (pure acetone, photolysis), show two signals, $\mathrm{P} 1$ and $\mathrm{P}^{\prime}{ }^{\prime}$ with retention time values of 


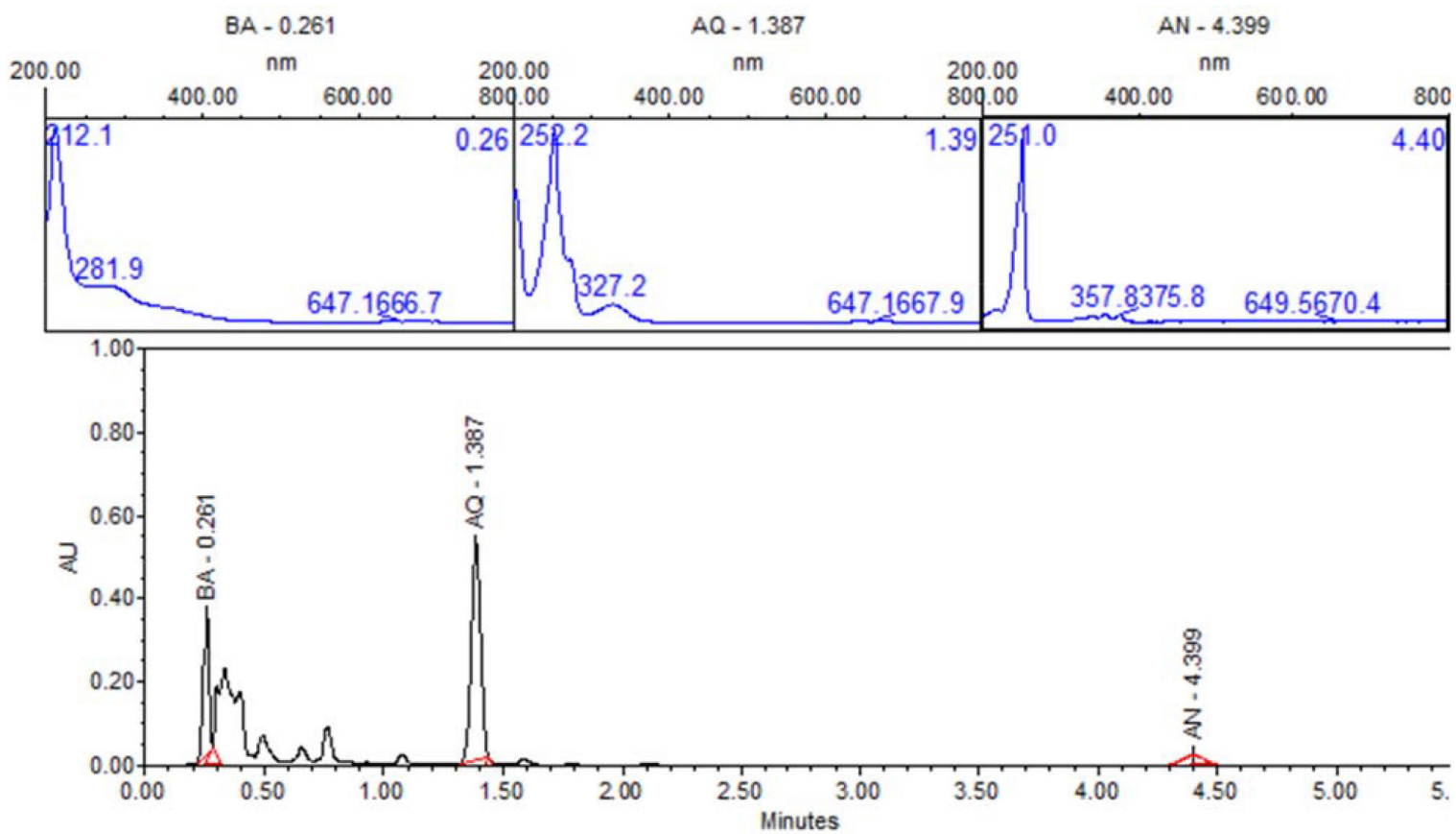

Figure 12. UPLC of sample-photocatalysis of anthracene with ZnO-ethanol:water pH 12. BA-Benzoic acid, AQ-9, 10-anthraquinone and AN-Anthracene

Table 1. Reaction-rate constants and order of reaction for the three systems studied using ethanol and acetone

$\begin{array}{lll}\text { Systems } & \begin{array}{c}\text { Reaction-rate } \\ \text { constant }(\mathrm{k})\end{array} & \begin{array}{c}\text { Order of } \\ \text { reaction }\end{array} \\ \mathrm{ZnO} / \text { light/EtOH: } \mathrm{H}_{2} \mathrm{O}\left(\mathrm{pH} \text { 12)/ } / \mathrm{C}_{14} \mathrm{H}_{10}\right. & 0.01323 \mathrm{~min}^{-1} \\ \text { Light/EtOH: } \mathrm{H}_{2} \mathrm{O}(\mathrm{pH} 12) / \mathrm{C}_{14} \mathrm{H}_{10} & 0.01269 \mathrm{~min}^{-1} & \\ \text { Light/EtOH} / \mathrm{C}_{14} \mathrm{H}_{10} & \text { No degradation } & -\end{array}$<smiles>c1ccc2cc3ccccc3cc2c1</smiles>

b)

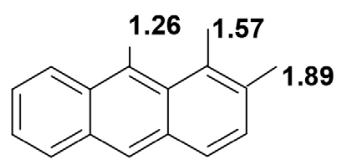

Figure 13. a) Numbering and $b$ ) $N_{u}$ (Dewar) values for substitution in different position of anthracene compound

0.461 and 0.434 minutes respectively. UV-vis spectra of these signals presented absorption maximum bands at 273 and $308 \mathrm{~nm}$, probably associated to simple polar byproducts, not detected in $\mathrm{CHCl}_{3}$ extracts analyzed with GC/MS. These results are in agreement with that reported by Mallakin et al.$^{41}$ However, in a future work, this should be confirmed by the development of specific chromatographic methods.

This work has demonstrated the non-innocent participation of

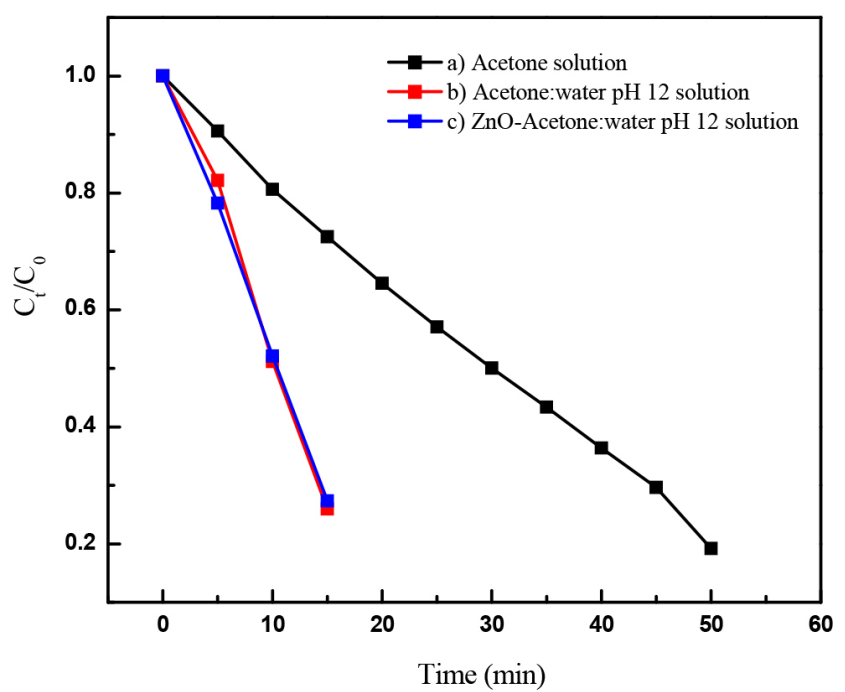

Figure 14. Anthracene degradation efficiency $\left(C / C_{0}\right)$ vs time graph in a) acetone solution, b) acetone:water $\mathrm{pH} 12$ solution and c) $\mathrm{ZnO}$ - acetone:water pH 12 solution, exposed to a $15 \mathrm{~W}$ UV lamp at $254 \mathrm{~nm}$, irradiation power $\left(31.4 \mu \mathrm{W} \mathrm{cm}^{-2}\right)$ 


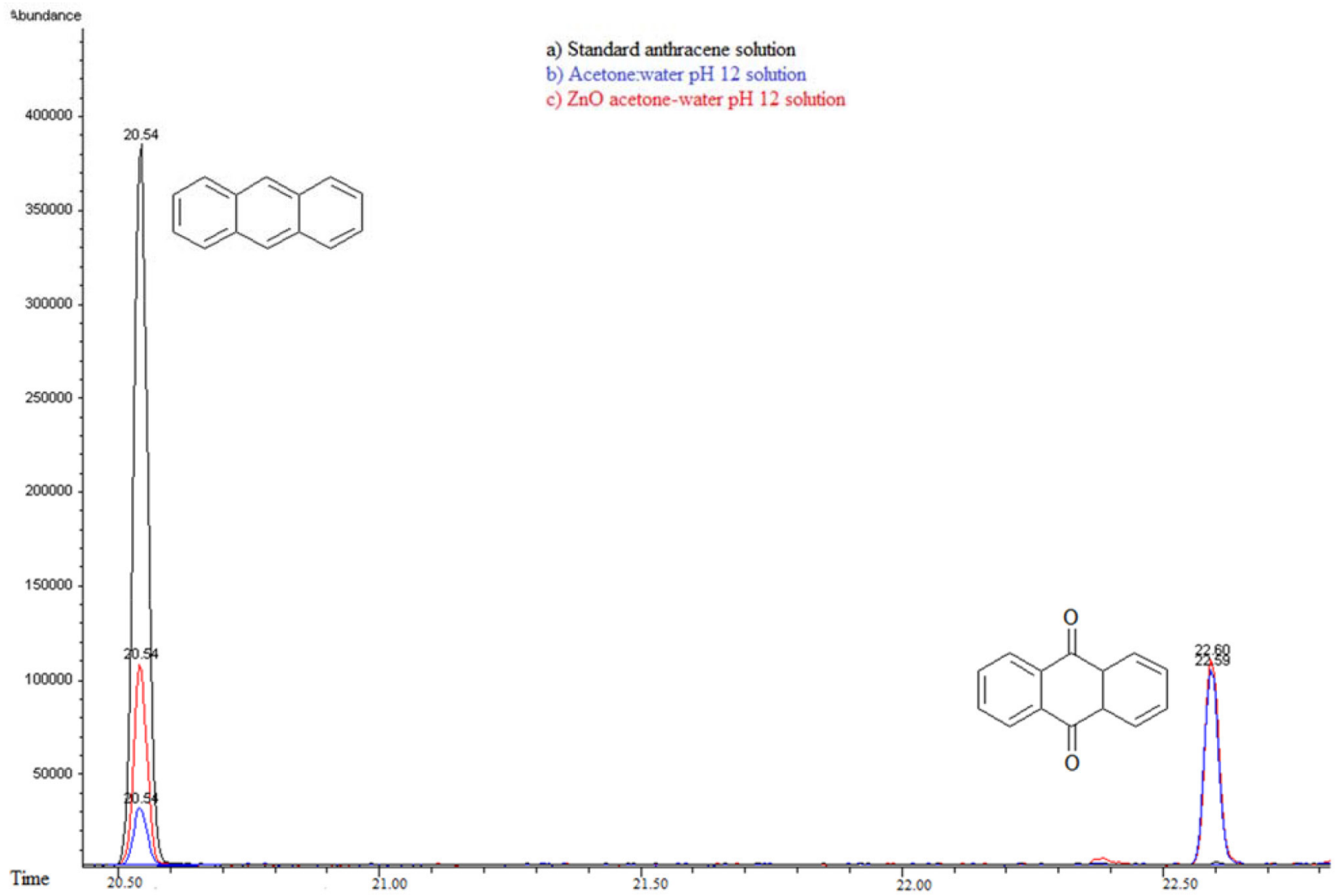

Figure 15. Gas Chromatography of a) Standard anthracene solution 20 ppm-acetone:water pH 12 solution, b) Photocatalysis anthracene and c) Photolysis anthracene

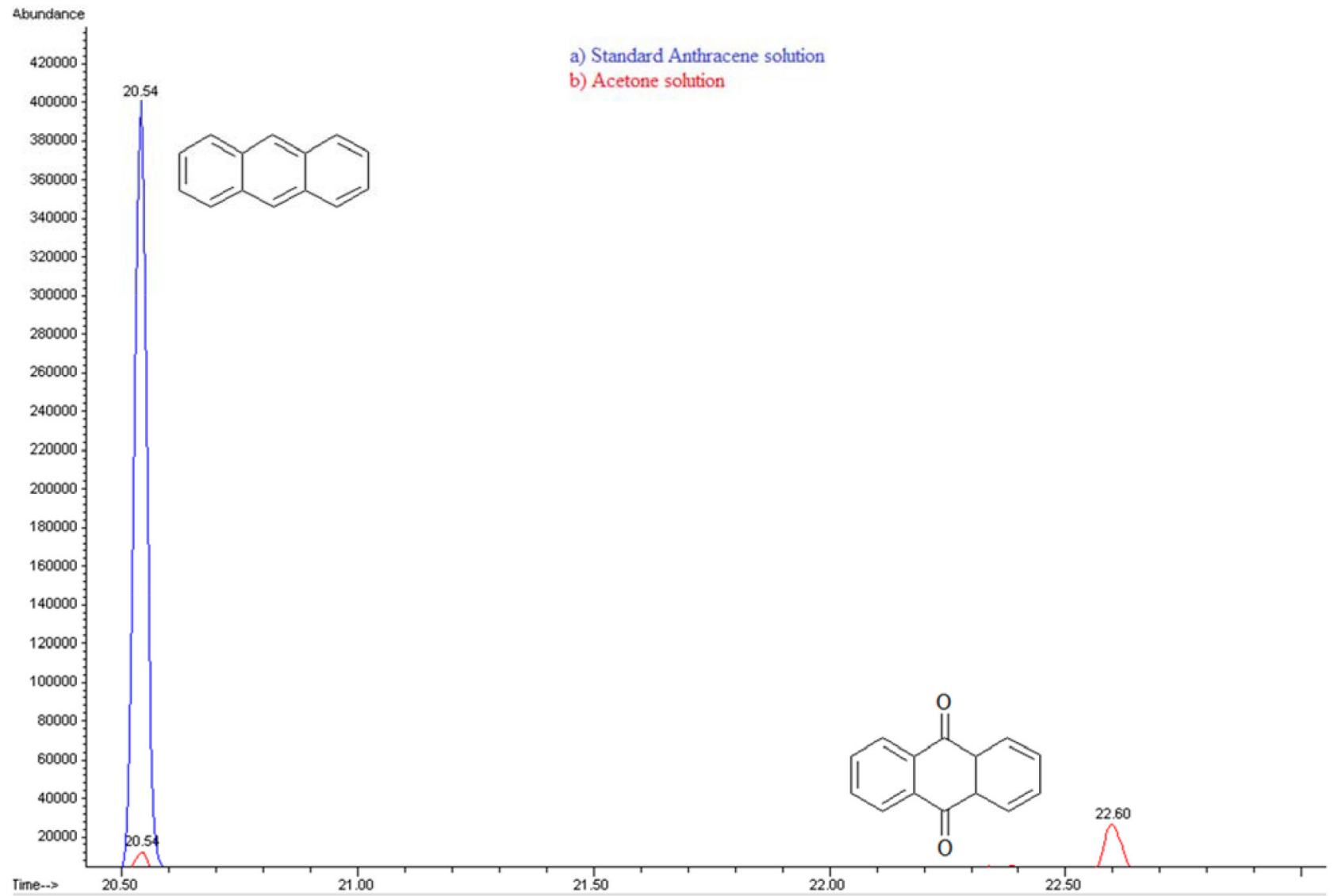

Figure 16. Gas Chromatography of a) Standard anthracene solution 20 ppm-acetone and b) Photolysis- Acetone solution 

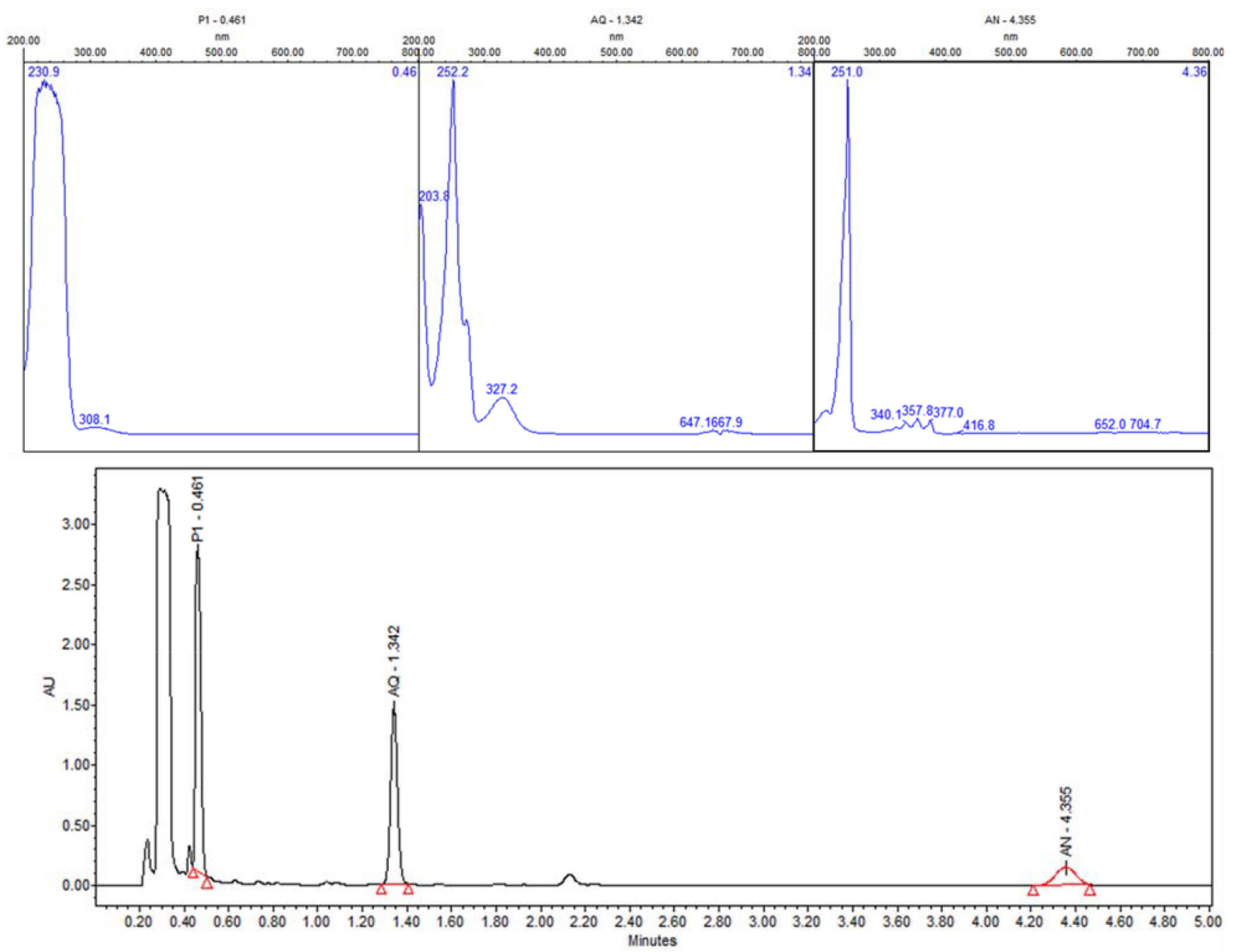

Figure 17. UPLC of sample-photocatalysis of anthracene with ZnO in acetone:water pH 12. P1-other products, AQ-9, 10-Anthraquinone and AN-Anthracene

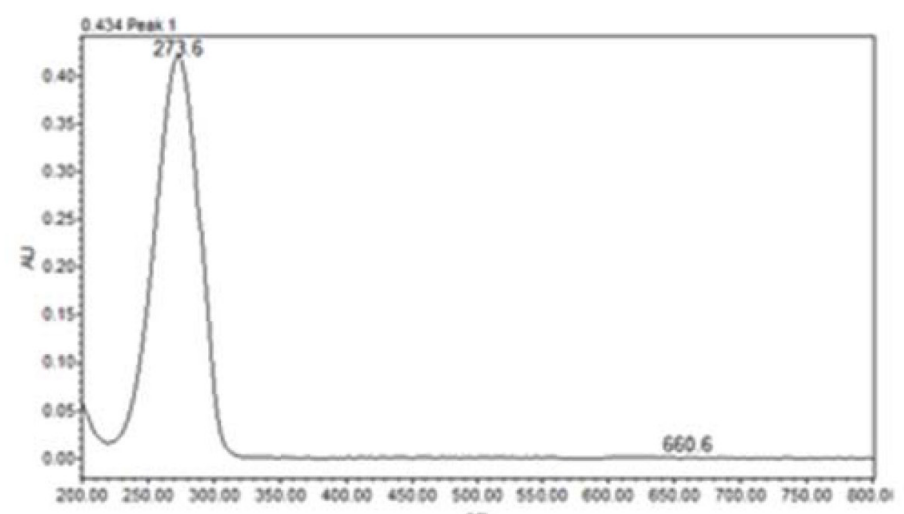
an

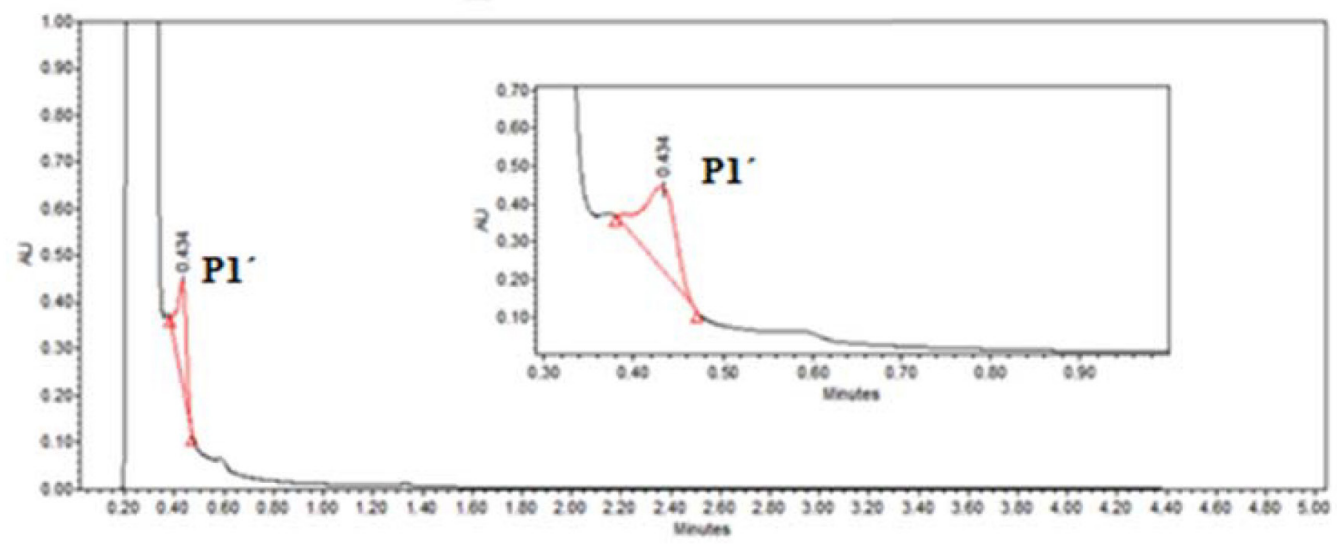

Figure 18. UPLC of sample-photolysis of anthracene in acetone 
Table 2. Reaction-rate constants and the order of reaction for the three systems studied using ethanol and acetone

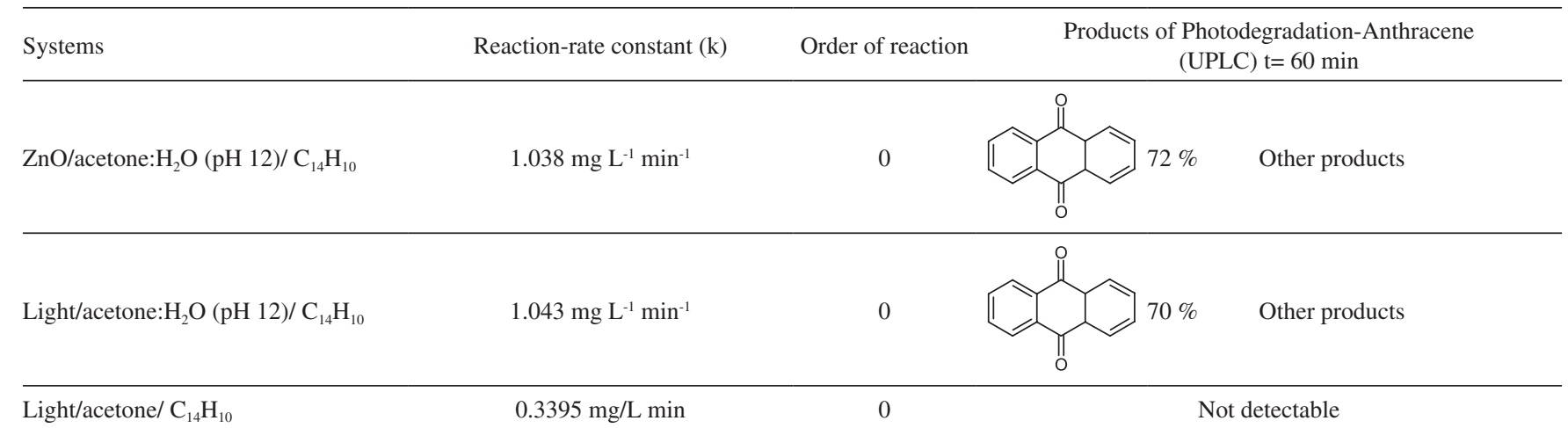

solvents in the photodegradation of anthracene in the presence of a typical semiconductor such as $\mathrm{ZnO}$. The photochemical behavior observed gives evidence to allow us to develop simpler methods for photocatalytic degradation of polycyclic aromatic hydrocarbons obtained from solid-liquid extraction of contaminated matrices, such as soils, with controlled reaction conditions.

\section{CONCLUSION}

It was possible to study the photodegradation of anthracene to understand the effect of solvent in the presence and absence of $\mathrm{ZnO}$ nanoparticles. Comparing the reaction pathways in acetone and ethanol, marked differences were observed. When $\mathrm{ZnO}$ was used in ethanol:water $\mathrm{pH} 12$ as reaction medium, colorless solutions with high oxidized products such as benzoic acid were detected due to photocatalysis and photolysis. In the case of ethanol:water $\mathrm{pH} 12$ with photolysis processes are presented. Moreover, pure ethanol has no important role in the photodegradation of anthracene. On the other hand photocatalytic systems using acetone:water $\mathrm{pH} 12$ solution the main product was the 9, 10-anthraquinone, with no participation of the semiconductor (occurring only photolysis). Finally, when acetone was use as reaction medium the photochemical transformation of the anthracene molecule yield probably simple polar byproducts.

\section{ACKNOWLEDGEMENTS}

The authors to thank SEP-CONACyT Research Program (Project CB-2009-130500, CB 2011-168032 and Project CONACyT grant 216315) for financial support; B. L. Martínez-Vargas and J. A. DíazReal acknowledge CONACyT for the scholarships. Also, authors thank Abigail Moreno, Rufino Nava Mendoza; UAQ (BET analysis), Hector Gabriel Silva Pereyra; LINAN-IPICYT (HR-TEM images).

\section{REFERENCES}

1. Yiu-Rui, W.; Zhu-Hua, L.; Vrijmuea, L. P.; Bioresour. Technol. 2010, $101,9666$.

2. Callahan, M. A.; Slimak, M. W.; Gabelc, N. W.; May, I. P.; Fowler, C. F.; Freed, J. R.; Jennings, P.; Durfee, R. L.; Whitmore, F. C.; Maestri, B.; Mabey, W. R.; Holt, B. R.; Gould, C.; Water-related Environmental Protection Agency, 1979, EPA-440/4-79-029.

3. Jin-Shao, Y.; Hua, Y.; Jing, Q.; Hui, P.; Hua-Ming, Q.; Na, Z.; Bao-Yon, H.; J. Hazard. Mater. 2011, 185, 174.

4. Kamat, P. V.; Huehn, R.; Nicolaescu, R.; J. Phys. Chem. B 2002, 106, 788.

5. Singh, A. K.; Adv. Powder Technol., 2010, 21, 609.
6. Hassan, S. M.; El Azab, W. I. M.; Ali, H. R.; Adv. Nat. Sci.: Nanosci. Nanotechnol. 2015, 6, 45012.

7. Vela, N.; Martínez-Menchón, M.; Pérez-Lucas, G.; Navarro, S.; J. Photochem. Photobiol., A 2012, 232, 32.

8. Kou, J.; Zhaadheng, L.; Young, G.; Jun, G.; Ming, Y.; Zhigang, Z.; J. Mol. Catal. A: Chem. 2010, 325, 48.

9. Karam F. F.; Falah, H.; Sadiq, J. B.; Ahmed F. H.; Ralf D.; Detelf B.; Int. J. Photoenergy 2014, Article ID 503825, 1.

10. Woo, O. T.; Chung, W. K.; Wong, K. H.; Chow, A. T.; Wong P. K.; J. Hazard. Mater. 2008, 168, 1192.

11. Lehto, K. M.; Vuorimaa, E.; Lemmetyinen, H.; J. Photochem. Photobiol., A 2000, 136, 53.

12. Peller, J.; Wiest, O.; Prashant, V. K.; J. Phys. Chem. A 2004, 108, 10925.

13. Fujishima, A.; Hashimoto, K.; Watanabe, T.; $\mathrm{TiO}_{2}$ photocatalysis: fundamentals and applications, BKC Inc.: Tokyo, 1999.

14. Sakata, T.; Kawai, T.; In Energy resources photochemistry and catalysis; Gratzel, M., ed.; Academic Press Inc.: USA, 1983.

15. Stroyuk, A. L.; Shvalagin, V.; Kuchmii, S. Y.; J. Photochem. Photobiol., A 2005, 173, 185.

16. Rietveld, H. M.; J. Appl. Crystallogr. 1969, 2, 65.

17. Rodríguez-Carvajal, J.; Phys. B (Amsterdam, Neth.) 1993, $192,55$.

18. Brus, L. E.; J. Chem. Phys. 1983, 79, 5566.

19. Brus, L. E.; J. Chem. Phys. 1984, 80, 4403.

20. Brus, L.; J. Phys. Chem. 1986, 90, 2555.

21. Nair, S. V.; Sinha, S.; Rustagi, K. C.; Phys. Rev. B 1987, 35, 4098.

22. Einevoll, G. T.; Phys. Rev. B 1992, 45, 3410.

23. Vanheusden, K.; Seager, C. H.; Warren, W. L.; Tallant, D. R.; Voigt, J. A.; Appl. Phys. Lett. 1996, 68, 403.

24. Lin, B.; Fu, Z.; Jia, Y.; Appl. Phys. Lett. 2001, 79, 943.

25. Zhao, Q. X.; Klason, P.; Willander, M.; Zhong, H. M.; Lu, W.; Yang, J. H.; Appl. Phys. Lett. 2005, 87, 211912

26. Subramanian, V.; Wolf, E. E.; Kamat, P. V.; J. Phys. Chem. B 2003, 107, 7479.

27. Rouquerol, J.; Avnir, D.; Fairbridge, C. W.; Everett, D. H.; Haynes, J. M.; Pernicone, N.; Ramsay, J. D. F.; Sing, K. S. W.; Unger, K. K.; Pure Appl. Chem. 1994, 66, 1739.

28. Nowak, M.; Kauch, B.; Szperlich, P.; Rev. Sci. Instrum. 2009, 80.

29. Berger, T.; Lana-Villareal, T.; Monllor-Satoca, D.; Gómez, R.; J. Phys. Chem. C 2007, 111, 9936.

30. Puigdomenech, I.; HYDRA; Hydrochemical Equilibrium-Constant Database Software, Royal Institute of Technology (KTH), Stockholm, Sweden, 2004.

31. Rubio Armendáriz, C.; Álvarez Marante, R.; Hardisson de la Torre, A.; Rev. Toxicol. 2006, 23, 1.

32. Debestani, R.; Ellis, K. J.; Sigma, M. E.; J. Photochem. Photobiol., A 1995, 86, 231. 
33. Espenson, J. H.; Chemical Kinetics and Reaction Mechanisms, $2^{\text {nd }}$ ed., McGraw-Hill: USA, 1995.

34. Gilbert, A.; Baggott, J.; Essentials of molecular photochemistry, Blackwell Scientific Publications Inc.: USA, 1991, pp. 355-369.

35. Gekhman, A. E.; Amelichkina, G. E.; Moiseeva, N.; Vargaftik, M.; J. Mol. Catal. A: Chem. 2000, 162, 111.

36. Johnson, R. E.; Quickenden, T. I.; J. Geophys. 1997, 102, 10985.
37. Shen, J.; Zhang, S.; Lian, J.; Kong, L.; Chen, J.; Acta Phys.-Chim. Sin. 2007, 23, 1531 .

38. Byung-Dae, L.; Masaaki, H.; Akihiko, M.; Water Sci. Technol. 1998, 38, 91.

39. Simeone, A.; Joseph, F.; Chem. Phys. Lett. 2000, 73, 179.

40. Dewar, M. J. S.; J. Am. Chem. Soc. 1952, 74, 3357.

41. Mallaki, A.; Dixon, G. D.; Chemosphere 2000, 40, 1435. 